\title{
Determining the Shape of Delivery Zones to Balance Local and Line Haul Costs
}

\author{
Bruce X. Wang* \\ Zachry Department of Civil Engineering, Dwight Look College of Engineering, Texas A\&M University, College Station, \\ TX 77843, USA
}

\begin{abstract}
This note follows an early work by Newell and Daganzo which suggests a wedge-like zone to divide a service area for freight delivery. Current literature has been largely using the zone of a fixed shape determined solely by demand density. We find that, given the same demand density, the shape of zones could vary significantly in order to better balance local and line haul truck delivery costs which include environmental externalities. A way to determine the optimal shape of truck delivery zones is presented.
\end{abstract}

Keywords: Freight distribution, continuous approximation, delivery zone, multiple vehicle routing problem.

\section{INTRODUCTION}

Continuous approximation in freight distribution is a simple and yet effective way to the large scale vehicle routing problems. Newell and Daganzo [1] suggest that a large area be divided into wedge-like zones, each zone containing a number of customers just enough for a truckload service. Fig. (1) illustrates this idea generally. A number of subsequent research are built on this concept [1-6]. In all these work except for Newell and Daganzo [4], the shape of the wedge is considered fixed for a demand density in order to minimize the total delivery distance within each zone. Newell and Daganzo [4] study shapes of delivery zones by combining the travel time on local and line haul roads. It finds that the optimal shape of delivery zones change when the line haul travel time is additionally considered. Our paper complements that earlier work in a limited sense by accounting for the overall cost based on ton-mileage on local and line-haul roads in deciding the delivery zone shape. We find that the delivery zone shapes also change when the relative comprehensive ton-mileage cost between local and line haul roads are considered. The comprehensive costs include legitimate external costs such as environmental pollution.

The rising energy cost and carbon footprint could dramatically change the picture about freight. Freight movement on major corridors and on local streets has different environmental externalities, which should be factored into carriers' routing decision and freight distribution planning. This particularly motivated development of this note.

\section{BRIEF SUMMARY OF PREVIOUS RESULTS}

In order to present our new result, it is necessary to introduce the basic results in the continuous approximation proposed by Daganzo [5] and an idea in Newell and Daganzo [1].

*Address correspondence to this author at the Zachry Department of Civil Engineering, Dwight Look College of Engineering, Texas A\&M University, College Station, TX 77843, USA; Tel: 979-845-9901;

E-mails: bwang@tamu.edu,bwang@civil.tamu.edu
Fig. (1) illustrates the ideas of zoning. Each vehicle goes from the depot (e.g. center of the region) to serve customers in one zone, and return to the depot in the end. Each zone in Fig. (1) is called a wedge because of its shape. But in this paper, we use wedge and zone interchangeably. The movement from the depot to a zone is referred to as line haul. The movement within a zone for delivery is called local travel in this paper.

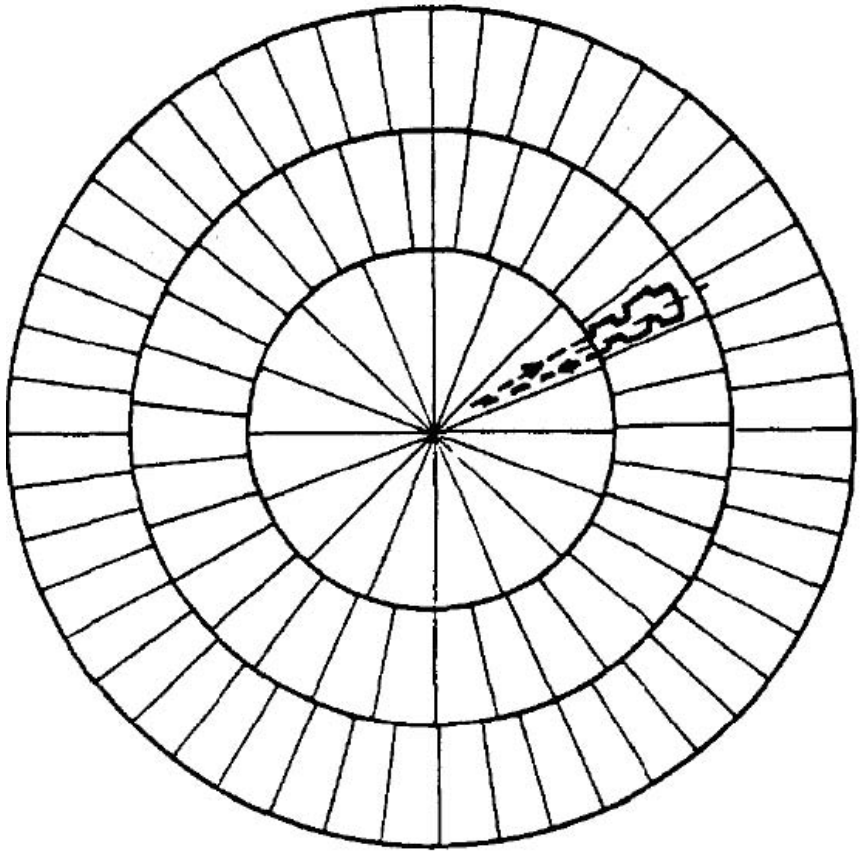

Fig. (1). A possible zoning for a Euclidean or ring-radial metric. (Source: Newell and Daganzo [1]).

Each zone is approximately a rectangular area called a wedge, and the routing within each zone follows the pattern of a swath. Fig. (1b) in Daganzo [5] illustrates a heuristic routing within a swath. Briefly, the heuristic goes horizontal first and vertical second in serving customers. It implies an optimal swath width $w^{*}$ to minimize the local distance in a zone, 


$$
w^{*}=\sqrt{\frac{3}{\delta}}
$$

where $\delta$ is the demand density in the service area, and $w$ is the width of the swath. The zone size is therefore decided to be $2 w^{*}$ wide with a length $L$, where $\mathrm{L}$ satisfies $2 w L \delta=C$.

This optimal width is derived in Daganzo [5], and has been used as the basis for designing delivery zones in subsequent research. In the following, we show how this width changes with different considerations of local and line haul shipping.

\section{DECIDING THE SHAPE WITH WEIGHTED DIS- TANCES}

Fig. (2) exemplifies what is in Fig. (1) regarding line haul versus local travel. As in literature, we use a rectangle to approximate a wedge.

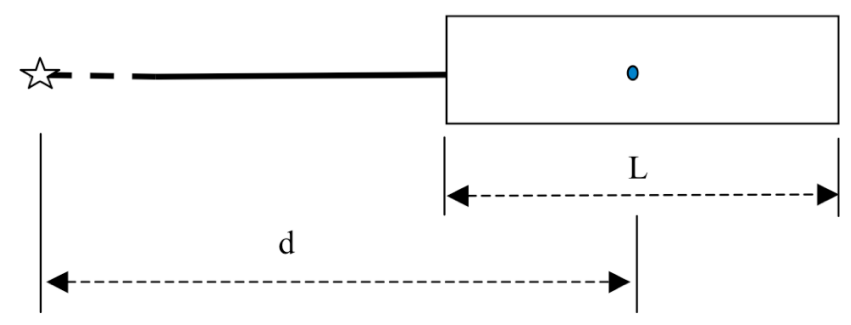

Fig. (2). Line haul vs local travel $\hat{i}^{\hat{\gamma}}=$ Depot, $\bullet=$ Centre of Market.

We assume a fixed distance $d$ from the depot to the center of a zone. We are allowed to change the shape of the zone, but not $d$. We maintain that the zone contain $C$ demand with $\mathrm{C}$ being capacity of a truck. Obviously, the line haul distance is $d-\frac{L}{2}$. The total local distance is $\left(\frac{w}{3}+\frac{1}{w \delta}\right) \times 2 w \delta L$, where $\left(\frac{w}{3}+\frac{1}{w \delta}\right)$ is the expected distance between two consecutively served customers in a zone (see details in Daganzo, 1984). Obviously on the line haul, the vehicle is at full load $g$. Over the local travel, the aver-

age vehicle load is half its full, $\frac{g}{2}$.

We consider the case in which the ton-miles in 'local' travel is weighted with a factor, $\alpha$. $\alpha$ is interpreted as the ratio of ton-mile cost on local travel versus that on line haul. The cost ideally includes wear and tear, carbon emission, labor hours, etc. Practically, $\alpha \geq 1.0$. In literature, Newell [3] considers item time on vehicle during delivery as well as the difference in cost between line haul and local delivery, very similar to this paper. However, it does not further explore for the opportunity of balancing line haul and local travel costs.

The following proposition summarizes our notion.

Proposition 1 If a ton-mile local travel has a cost $\alpha$ times that of a ton-mile on line haul, the optimal width of a wedge in dividing a service area is $w^{*}=\sqrt{\frac{3(2 \alpha-1)}{2 \alpha \delta}}$ when $w^{*} \geq \frac{C}{4 \delta}$.

Proof

Clearly, the condition $d-\frac{L}{2} \geq 0$ requires that $w^{*} \geq \frac{C}{4 \delta}$.

The expected weighted ton-miles for the entire delivery based on Fig. (2) is as follows,

$\left(\frac{w}{3}+\frac{1}{w \delta}\right) \times 2 w \delta L \times \frac{g}{2} \times \alpha+\left(d-\frac{L}{2}\right) \times g$.

In (3), the first term is for the weighted local ton-miles. The second term is for the line haul ton miles. (3) can be further simplified into,

$\frac{w C}{3} \times \frac{g}{2} \times \alpha+\left(\alpha-\frac{1}{2}\right) g L+d g$
$=\frac{\alpha w g C}{6}+\frac{(2 \alpha-1) g C}{4 w \delta}+d g$,

where $d g$ is a constant. Minimization is mainly about the sum of the first two terms. By taking first order derivative on $w$, Proposition 1 is proved. [End of proof].

Observation 1. The optimal width $w^{*}$ increases with $\alpha$. The optimal width in (1) found in Daganzo [5] corresponds to a very large $\alpha$, which implies a heavy preference to minimizing the local travel first.

Observation 2. If one local mile is considered equivalent to a line haul mile regardless of vehicle load, which implies an $\alpha=2.0$, the optimal width is $w^{*}=\frac{3}{2 \sqrt{\delta}}$.

Observation 2 is better explained this way. When $\alpha=2.0$, the optimum of $w$ in the total cost function (3) is the same as in $\left(\frac{w}{3}+\frac{1}{w \delta}\right) \times 2 w \delta L+\left(d-\frac{L}{2}\right)$. The latter is the overall mileages for the case mentioned in Observation 2. In this case, the zone is over $15 \%$ narrower than in Daganzo [5]. In addition, $\alpha=1.0$ would make a zone $30 \%$ narrower. Note that when vehicle tare is considered, the $\alpha$ value would be smaller, the reduction of $\alpha$ depends on the ratio between the full load and the tare.

The wedge length $L$ is also obtainable with the optimal width $w^{*}$. All the wedges in Fig. (1) except those adjacent to the center have the same size as calculated here. In the derivations above, we assume $d \geq \frac{L}{2}$. If calculation leads to a width such that the depot falls within a zone, we set the width such that $d=\frac{L}{2}$.

\section{CONCLUSIONS}

The difference of cost between line and local hauls influences the shape of service zones. We present a method to 
decide the zone shape by balancing these two costs. What matters in our method is the ratio between the ton-mile cost on local travel and that on line haul.

Freight cost and environmental concerns make this work meaningful. The resulting shape of zones can still be adopted in Daganzo [6] and Ouyang [2] among others. Of course, implementation results would be different. From this paper, one might be able to feel the impact of environmental consideration on the distribution system operations in terms of vehicle mileages, fuel consumption and gas emission.

\section{REFERENCES}

[1] G.F. Newell, C.F Daganzo, "Design of multiple-vehicle delivery tours - I: a ring-radial network". Transport. Res. B, Vol. 20(5), pp. 345-364, 1986a.

[2] Y. Ouyang, "Design of vehicle routing zones for large-scale distribution systems", Transport. Res. B, Vol. 41, pp. 1079-1093, 2007.

[3] G.F. Newell, "Design of multiple-vehicle delivery tours - III: valuable goods", Transport. Res. Part B, Vol. 20 (5), pp.377-390, 1986.

[4] G.F. Newell, C.F. Daganzo, "Design of multiple-vehicle delivery tours - II: other metrics", Transport. Res. B, Vol. 20(5), pp. 365376, 1986b.

[5] C. Daganzo, "The length of tours in zones of different shapes", Transport. Res. B, Vol. 18(2), pp. 135-145, 1984a.

[6] C.F. Daganzo, "The distance traveled to visit $\mathrm{N}$ points with a maximum of C stops per vehicle: an analytic model and an application”, Transport. Sci., Vol. 18 (4), pp. 331-350, 1984b.

(C) Bruce X. Wang; Licensee Bentham Open.

This is an open access article licensed under the terms of the Creative Commons Attribution Non-Commercial License (http://creativecommons.org/licenses/by$\mathrm{nc} / 3.0 /$ ) which permits unrestricted, non-commercial use, distribution and reproduction in any medium, provided the work is properly cited. 